\title{
Possible mechanisms for the coupling between late spring sea surface temperature anomalies over tropical Atlantic and East Asian summer monsoon
}

\author{
Yeon-Woo Choi ${ }^{1} \cdot$ Joong-Bae Ahn ${ }^{1}$ (D)
}

Received: 25 January 2019 / Accepted: 29 August 2019 / Published online: 6 September 2019

(c) The Author(s) 2019

\begin{abstract}
The relationship between the preceding late spring Sea Surface Temperature (SST) over the tropical Atlantic and the East Asian Summer Monsoon (EASM) is investigated based on the observational data and Coupled Model Intercomparison Project Phase 5 (CMIP5) historical simulations. The results show that warm (cold) tropical Atlantic SST (TASST) during May tends to be followed by a strong (weak) EASM with positive (negative) precipitation anomalies over the subtropical frontal area. Evidence is also provided that the atmospheric teleconnections propagating in both east and west directions are the key mechanisms linking the EASM with the preceding May TASST. That is, the warm TASST anomaly during late spring can persist through the subsequent summer, which, in turn, induces the Gill-type Rossby wave response in the eastern Pacific, exciting the westward relay of the Atlantic signal, as well as the eastward propagation of the Rossby wave along the jet stream. Furthermore, the westward (eastward) propagating teleconnection signal may induce the anomalous anticyclone in the lower troposphere over the Philippine Sea (anomalous tropospheric anticyclone with barotropic structure over the Okhotsk Sea). The anomalous anticyclonic circulation over the Philippine Sea (Okhotsk Sea) brings warm and humid (cold) air to higher latitudes (lower latitudes). These two different types of air mass merge over the Baiu-Meiyu-Changma region, causing the enhanced subtropical frontal rainfall. To support the observational findings, CMIP5 historical simulations are also utilized. Most state-of-the-art CMIP5 models can simulate this relationship between May TASST and the EASM.
\end{abstract}

Keywords Tropical Atlantic sea surface temperature $\cdot$ EASM $\cdot$ CMIP5 $\cdot$ Atmospheric teleconnection

\section{Introduction}

The climate in Northeast Asia, including the Korean peninsula, China, and Japan, is strongly affected by the East Asian Summer Monsoon system (EASM) known as Baiu in Japan, Changma in Korea, and Meiyu in China (BCM, Hong and Ahn 2015). The strong (weak) EASM is generally accompanied by a strengthened (weakened) western North Pacific subtropical high, resulting in abundant (deficient) rainfall along the subtropical monsoon front during boreal summer (e.g., Huang and Sun 1992; Chang et al. 2000; Lee et al. 2006; Wang et al. 2008a). The variation of the EASM

Joong-Bae Ahn

jbahn@pusan.ac.kr

1 Division of Earth Environmental System, Pusan National University, 2, Busandaehak-ro 63beon-gil, Geumjeong-gu, Busan 46241, Republic of Korea system can cause extreme events such as droughts and floods, leading to regional socio-economic consequences (Zhou et al. 2009; Huang and Wu 1989; Seo et al. 2012).

The interannual variability of the EASM has been researched to be influenced by various factors, such as El Nino-Southern Oscillation (ENSO; e.g., Wang et al. 2000; Wu et al. 2009, 2012; Yun et al. 2010; Kim and Kug 2018), the Indian summer monsoon (Wang et al. 2001), Indian Ocean Sea Surface Temperature (SST; e.g., Yang et al. 2007; Xie et al. 2009; Yun et al. 2010; Park et al. 2018), Okhotsk blocking (e.g., Wu et al. 2009; Park and Ahn 2014), Arctic Oscillation (e.g., Gong and Ho 2003; Gong et al. 2011), and North Atlantic Oscillation (NAO; e.g., Sung et al. 2006; Wu et al. 2009, 2012; Sun and Wang 2012; Zuo et al. 2013; Zheng et al. 2016).

Recently, several studies showed that the EASM is highly correlated with the North Atlantic SST variability from the preceding winter to summer based on observations and model experiments (Wu et al. 2009, 2012; Zuo et al. 2013; 
Zheng et al. 2016). Wu et al. (2009) established an empirical model to predict the EASM variability by combining two predictors: ENSO and spring NAO. They suggested that NAO-related spring SST anomalies in the North Atlantic can persist throughout summer and induce anomalous anticyclonic circulations over the Ural Mountains and the Okhotsk Sea through downstream development of subpolar teleconnections. The anomalous anticyclonic circulation over the Okhotsk Sea tends to strengthen the subtropical monsoon front. Zuo et al. (2013) also showed that the EASM variability is more closely coupled with the North Atlantic tripolar SST anomalies in the preceding spring than in the simultaneous summer. Similarly, Zheng et al. (2016) found that evolution of the NAO-related SST signal from spring through summer can affect the predictability of the EASM. In addition, the linkage between the summer NAO signal and the East Asian summer rainfall is more evident after the late $1970 \mathrm{~s}$, along with the decadal change of the NAO (Sun and Wang 2012).

Several recent studies have newly suggested that Tropical Atlantic SST (TASST) itself can affect the climate variability in the Northern Hemisphere during subsequent seasons (Sun et al. 2009; Ham et al. 2013a, b, 2017; Ham and Kug 2015). Sun et al. (2009) found that the decadal variability of the tropical Atlantic SST can impact on the Northern Hemispheric atmospheric circulations during summer. Ham et al. (2013a, b) showed that north TASST could trigger a Central-Pacific (CP)-type ENSO (also known as ENSO Modoki; Ashok et al. 2007) during boreal winter. They insisted that warm (cold) TASST anomalies during the preceding spring can induce easterly (westerly) wind anomalies over the western equatorial Pacific in the following months through westward relay of the Atlantic signal. These easterly (westerly) wind anomalies can in turn initiate CP-type El Nino (La Nina) events during the subsequent winter. On the basis of historical Coupled Model Intercomparison Project Phase 3 and Phase 5 (CMIP3 and CMIP5) simulations, Ham and Kug (2015) showed that most state-of-the-art climate models can simulate the observed relationship between spring north TASST and ENSO during the following winter. In addition to the Atlantic SST-ENSO link, Ham et al. (2017) revealed that the TASST variability can also influence the Korean summer precipitation.

Based on these aforementioned studies, TASST generally persists from the preceding spring through the following summer due to the oceanic thermal memory, and its signal can be transmitted to the western Pacific through teleconnections (Wu et al. 2009, 2012; Zuo et al. 2013; Ham et al. 2013a, 2017; Ham and Kug 2015; Zheng et al. 2016). Thus, it is reasonable to expect that late spring TASST may act as a precursor of the summertime climate variability, particularly the EASM. However, most existing studies merely focused on the relationship between the EASM and the SST tripole in the North Atlantic (Wu et al. 2009, 2012; Zuo et al. 2013; Zheng et al. 2016), rather than TASST. Although Ham et al. (2017) mentioned that the subtropical monsoon front, Changma, can be affected by summer TASST, their study was confined to Korean precipitation and was focused on the concurrent relationship between them. In this study, we examine the remote impact of springtime TASST on the subsequent EASM variability.

The paper is outlined as follows. In Sect. 2, we briefly describe the primary dataset and CMIP5 models used. The linkage between spring TASST and the EASM variability is addressed in Sect. 3. Section 4 describes the possible mechanisms of the remote impact of TASST on the EASM by using the observational dataset and CMIP5 historical simulations. The summary and conclusions are given in Sect. 5 .

\section{Data}

We used the monthly mean air temperature, horizontal wind, and geopotential height fields from the Modern-Era Retrospective Analysis for Research and Applications (MERRA) reanalysis dataset with $1.25^{\circ} \times 1.25^{\circ}$ horizontal resolution (Rienecker et al. 2011) for the period 1979-2015. The monthly precipitation data were taken from the Global Precipitation Climatology Project (GPCP; Adler et al. 2003) version 2.2. In order to support our results derived from the GPCP precipitation data, we also utilized monthly mean precipitation data from 59 Korean weather stations for the same period. In addition, the monthly mean SST data were obtained from the Hadley Centre Sea Ice and Sea Surface Temperature (HadISST) dataset gridded at $1^{\circ} \times 1^{\circ}$ resolution (Rayner et al. 2003).

Following the recommendation of Wang et al. (2008a), the reversed Wang and Fan index (hereafter EASMI) was calculated to represent the strength of the EASM. This index was defined by the U850 $\left(22.5^{\circ}-32.5^{\circ} \mathrm{N}, 110^{\circ}-140^{\circ} \mathrm{E}\right)$ minus $\mathrm{U} 850\left(5^{\circ}-15^{\circ} \mathrm{N}, 90^{\circ}-130^{\circ} \mathrm{E}\right)$, where U850 denotes the zonal wind at $850-\mathrm{hPa}$. The wintertime (December-February; DJF) Nino3.4 index was obtained from the NOAA Climate Prediction Center website (http://www.cpc.ncep.noaa.gov/). In addition, the horizontal wave activity fluxes (WAF), which represent the propagation of quasi-stationary Rossby waves, were estimated as described by Takaya and Nakamura (2001). To identify the role of the TASST in the modulation of eastward propagating Rossby waves, Rossby Wave Sources (RWS) were derived from the quasi-geostrophic vorticity equation following the previous studies (Sardeshmukh and Hoskins 1988; Jin and Hoskins 1995; Lim 2015). Prior to the analysis all data were detrended.

In order to support the observational hypothesis that the late spring SST anomalies over the tropical Atlantic can potentially affect the subsequent EASM, we utilized the 
Table 1 CMIP5 models used in this study

\begin{tabular}{|c|c|c|c|}
\hline Model name & Institute & Country & Ensemble member \\
\hline ACCESS1_0 & CSIRO-BOM & Australia & r1i1p1 \\
\hline ACCESS1_3 & CSIRO-BOM & Australia & r1ilp1 \\
\hline CMCC_CESM & $\mathrm{CMCC}$ & Italy & r1i1p1 \\
\hline CMCC_CM & CMCC & Italy & r1i1p1 \\
\hline CMCC_CMS & $\mathrm{CMCC}$ & Italy & r1i1p1 \\
\hline CNRM_CM5_2 & $\begin{array}{l}\text { CNRM-CER- } \\
\text { FACS }\end{array}$ & France & r1i1p1 \\
\hline CSIRO_Mk3_6_0 & CSIRO-QCCCE & Australia & r1ilp1 \\
\hline GFDL_CM2p1 & NOAA, GFDL & USA & r1i1p1 \\
\hline GFDL_CM3 & NOAA, GFDL & USA & r1i1p1 \\
\hline GFDL_ESM2G & NOAA, GFDL & USA & r1i1p1 \\
\hline GFDL_ESM2 M & NOAA, GFDL & USA & r1i1p1 \\
\hline GISS_E2_H & NASA/GISS & USA & r1ilp1 \\
\hline GISS_E2_H_CC & NASA/GISS & USA & r1ilp1 \\
\hline GISS_E2_R & NASA/GISS & USA & r1i1p1 \\
\hline GISS_E2_R_CC & NASA/GISS & USA & r1i1p1 \\
\hline HadCM3 & MOHC & UK & r1i1p1 \\
\hline HadGEM2_AO & NIMR-KMA & Korea & r1ilp1 \\
\hline HadGEM2_CC & $\mathrm{MOHC}$ & UK & r1ilp1 \\
\hline HadGEM2_ES & MOHC & UK & r1i1p1 \\
\hline INMCM4 & INM & Russia & r1ilp1 \\
\hline IPSL_CM5A_LR & IPSL & France & r1i1p1 \\
\hline $\begin{array}{l}\text { IPSL_CM5A_ } \\
\text { MR }\end{array}$ & IPSL & France & r1i1p1 \\
\hline IPSL_CM5B_LR & IPSL & France & r1i1p1 \\
\hline MIROC_ESM & JAMSTEC & Japan & r1ilp1 \\
\hline $\begin{array}{l}\text { MIROC_ESM_ } \\
\text { CHEM }\end{array}$ & JAMSTEC & Japan & r1i1p1 \\
\hline MIROC5 & JAMSTEC & Japan & r1ilp1 \\
\hline MPI_ESM_LR & MPI-M & Germany & r1i1p1 \\
\hline MPI_ESM_MR & MPI-M & Germany & r1i1p1 \\
\hline MPI_ESM_P & MPI-M & Germany & r1i1p1 \\
\hline MRI_CGCM3 & MRI & Japan & r1i1p1 \\
\hline NorESM1_ME & $\mathrm{NCC}$ & Norway & r1ilp1 \\
\hline
\end{tabular}

CMIP5 historical simulations. For the ensemble analysis, the results of all models were interpolated onto the MIROCESM grid, which has the lowest-resolution $(\mathrm{T} 42 ; 128 \times 64)$ among 31 CMIP5 CGCMs. Only the first ensemble member of each model was considered. Detailed descriptions of the CMIP5 CGCMs used are summarized in Table 1.

\section{Relationship between late spring TASST and the EASM}

To identify the spatial distribution of summer precipitation anomalies associated with the EASMI, regression analysis was conducted for the period 1979-2015 (Fig. 1). The regression map of the precipitation anomalies on the EASMI yields a meridional tripole pattern over East Asia, consistent with previous studies (e.g., Wang et al. 2008a; Wu et al. 2009). The positive precipitation anomalies prevail over the BCM frontal area and Maritime Continent. Meanwhile, the negative precipitation anomalies are located over the western North Pacific. In addition to the tripole pattern, positive (negative) precipitation anomalies appear in the tropical Atlantic and Indian Oceans (the Okhotsk Sea and vicinity of the Nino3.4 region). Particularly, the significant positive precipitation anomalies associated with the EASM are located over the Atlantic Inter-Tropical Convergence Zone (ITCZ) region. According to previous studies (Ham et al. 2013a, b; Ham and Kug 2015), the positive precipitation anomalies over the tropical Atlantic during boreal summer (Fig. 1) are closely associated with the strengthened Atlantic ITCZ, and are known to be affected by TASST anomalies during the preceding spring. This implies that the EASM could be predicted by the preceding spring SST over the tropical Atlantic.

To assess the linkage between late spring (May) SST anomalies and the subsequent EASM, the map of May SST regressed on the EASMI was computed (Fig. 2a). The significant positive SST anomalies associated with the EASMI
Fig. 1 Regression map of the summer (JJA) precipitation anomaly (Unit: $\mathrm{mm} /$ day) on the East Asian Summer Monsoon index (EASMI). The dots indicate the areas where the correlation coefficients are significant at the $90 \%$ confidence level

\section{Reg of JJA PR on EASMI}

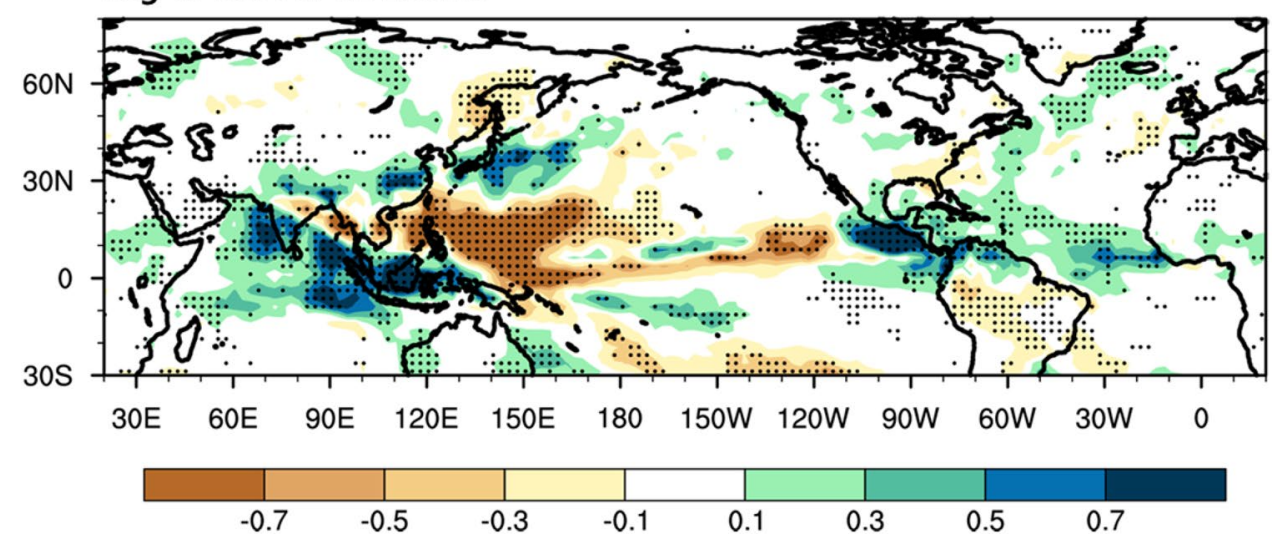


Fig. 2 a Regression map of the May SST anomaly (Unit: ${ }^{\circ} \mathrm{C}$ ) on the EASMI. b Time series of the normalized EASMI, May TASST, and DJF Nino3.4. c Partial correlation coefficients between monthly TASSTs and the EASMI after excluding the effect of the preceding DJF Nino3.4. The dots in (a) indicate the areas where the correlation coefficients are significant at the $90 \%$ confidence level. The blue (red) dots in (c) denote that the correlations are significant at the $95 \%$ (99\%) confidence level (a) Reg of May SST on EASMI

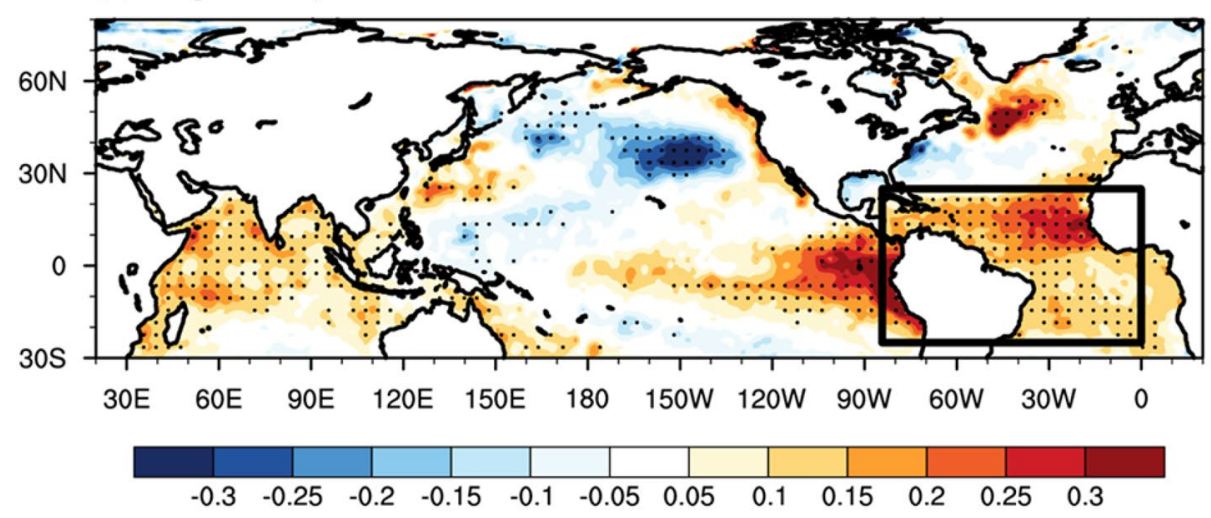

(b) Normalized time series

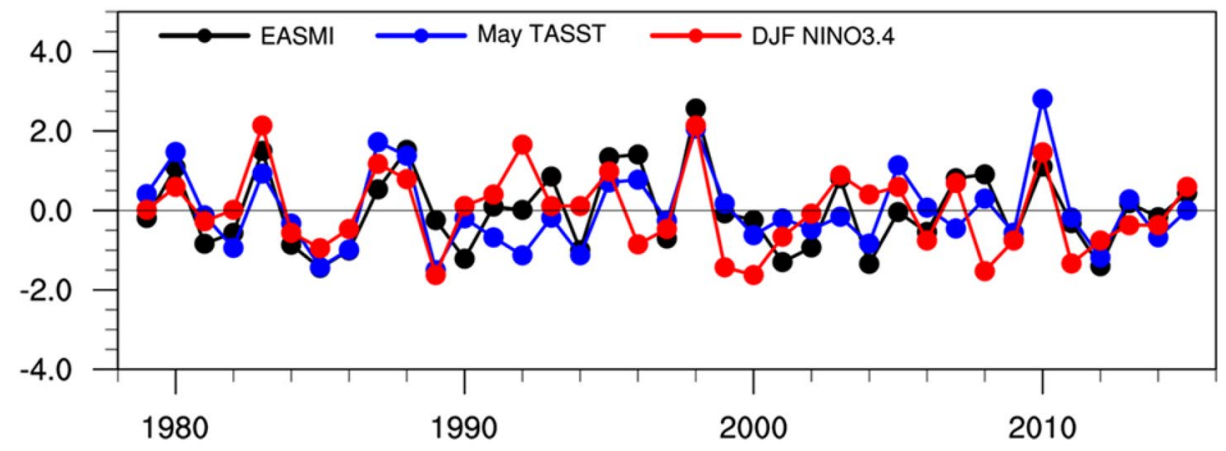

(c) ParCorr btw monthly TASSTs and EASMI without DJF NINO3.4

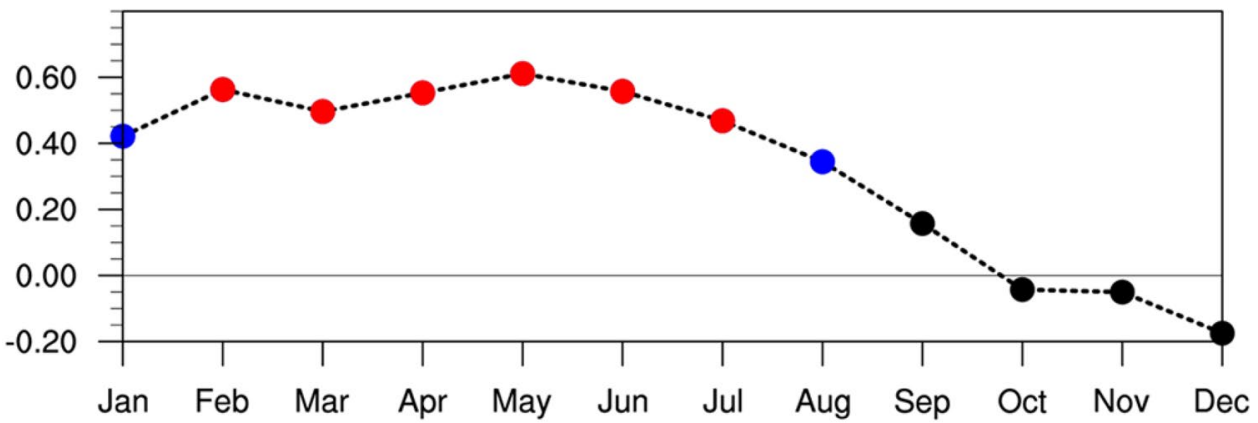

are located over the Atlantic with the maximum centered in the north tropical Atlantic (black rectangle in Fig. 2a), suggesting that the EASM variability may be controlled by the long-lived TASST. Although the TASST anomalies shown in Fig. 2a bear some resemblance with the southernmost part of the North Atlantic SST tripole pattern (e.g., Figure 5 of $\mathrm{Wu}$ et al. 2009), they cover a wider area $\left(25^{\circ} \mathrm{S}-25^{\circ} \mathrm{N}\right)$ than the southern pole of the tripole pattern $\left(0^{\circ}-30^{\circ} \mathrm{N}\right)$. In addition, there are positive SST anomalies in the Indian Ocean, which precede the summers of the positive EASMI polarity (Yang et al. 2007; Xie et al. 2009). However, the discussion on this relationship is beyond the scope of this study.

To quantitatively clarify this relationship between May TASST and the EASM, we define the May TASST index by area averaging the SST anomalies over the region $\left(25^{\circ} \mathrm{S}-25^{\circ} \mathrm{N}, 84^{\circ} \mathrm{W}-0^{\circ}\right)$, a region where the correlation coefficients exceed the $95 \%$ confidence level. Figure $2 \mathrm{~b}$ shows the time series of the normalized EASMI, May TASST, and DJF Nino3.4 indices for the period 1979-2015. It is clear that these three indices significantly covariate over the analysis period with a correlation coefficient of $0.72(0.54)$ between the EASMI and May TASST (DJF Nino3.4), which is significant at the $99 \%$ confidence level. Also, May TASST has a significant positive correlation with the preceding DJF Nino3.4, as identified by previous studies (e.g., Alexander and Scott 2002).

To isolate the unique contribution of May TASST to the EASM, independent of the preceding DJF Nino3.4, we performed partial correlation analysis. Figure $2 \mathrm{c}$ shows the partial correlation coefficients between the EASMI and monthly 
TASSTs, excluding the effect of the preceding DJF Nino3.4. As shown, the EASMI is significantly correlated with the monthly TASSTs from February to July. In particular, there is strong covariability between the series of May TASST and the EASM, with a correlation coefficient of 0.61 , which is significant at the $99 \%$ confidence level based on a Student's $t$ test. These statistical results suggest that May TASST can potentially affect the EASM with 1-month time lag.

In order to support this result, partial regression analysis was applied. Figure 3 shows the partial regression of summer (June-July-August; JJA) precipitation anomalies on the normalized May TASST after excluding the influence of the DJF Nino3.4, following the similar method by Ham et al. (2013a, b) and Ham and Kug (2015). The pattern of the GPCP precipitation anomalies associated with May TASST yields the meridional tripole pattern (Fig. 3a) resembling the regression map shown in Fig. 1. The positive (negative) precipitation anomalies are located over the subtropical frontal area and Maritime Continent (western North Pacific). This result is also confirmed by the analysis of in situ precipitation data (Fig. 3b). Generally, positive precipitation anomalies are observed over South Korea during the boreal summer season. In particular, northwestern South Korea features significant positive anomalies, which is to some extent consistent with those reported by Ham et al. (2017).

Figure $4 \mathrm{a}$ and $\mathrm{c}$ show the regression maps of JJA geopotential height anomalies at $500-\mathrm{hPa}$ and $850-\mathrm{hPa}$ on the normalized EASMI, respectively. In the Eurasian Continent, a wave-like pattern is clearly seen, especially in the upper (not shown) and middle troposphere (Fig. 4a). This pattern exhibits a quasi-barotropic structure with positive (negative) geopotential anomalies in the Ural Mountains and the Okhotsk Sea (central Europe and Siberia, particularly to the northwest of Lake Baikal). In addition to the zonal wave-train pattern, a Pacific-Japan teleconnection pattern (Nitta 1987) extending from south to north is found along the coastal region of East Asia. These two teleconnection patterns are consistent with those of previous studies (e.g., Wu et al. 2009; Li et al. 2018). Similarly, the 1-month lag responses of JJA circulation to the preceding May TASST, excluding the effect of the preceding DJF Nino3.4 (Fig. 4b and d) closely resemble the summer monsoon system over East Asia shown in Fig. 4a and c. It suggests that May TASST contributes significantly to the EASM circulation.

Singular value decomposition (SVD) analysis (Bretherton et al. 1992; Choi et al. 2016) was performed to determine the coupled modes of variability between JJA precipitation and May SST fields. Figure 5 shows heterogeneous correlation patterns and the time series of the corresponding Expansion Coefficients (EC) of the first coupled SVD modes for May SST (SST EC1) and the summer precipitation (PR EC1). The leading SVD mode explains $55.4 \%$ of the total covariance, and the temporal correlation coefficient between the two expansion coefficients is 0.68 , which is significant at the $99 \%$ confidence level. The leading SVD mode of JJA precipitation variability yields the meridional tripole pattern that closely resembles the regression pattern shown in Figs. 1a and 3a. The correlation coefficient between the time series of the PR EC1 and the EASMI is 0.92 , which exceeds the $99 \%$ confidence level. The leading coupled mode of the May SST variability bears a strong resemblance with the regression map shown in Fig. 2a with the correlation coefficient being 0.88
Fig. 3 Partial regression maps of the summer precipitation anomalies (Unit: $\mathrm{mm} /$ day) on May TASST after excluding the effect of the preceding DJF Nino3.4; (a) and (b) are from GPCP and 59 weather station data maintained by the Korea Meteorological Administration, respectively. The dots in (a) and the red circles in $(\mathbf{b})$ indicate the areas where the correlation coefficients are significant at the $90 \%$ confidence level (a) ParReg, GPCP JJA PR

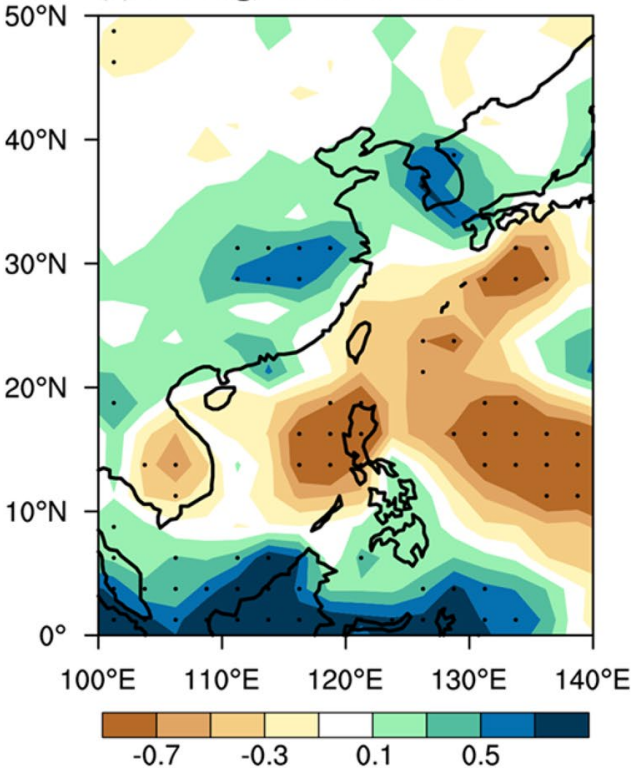

(b) ParReg, STA JJA PR

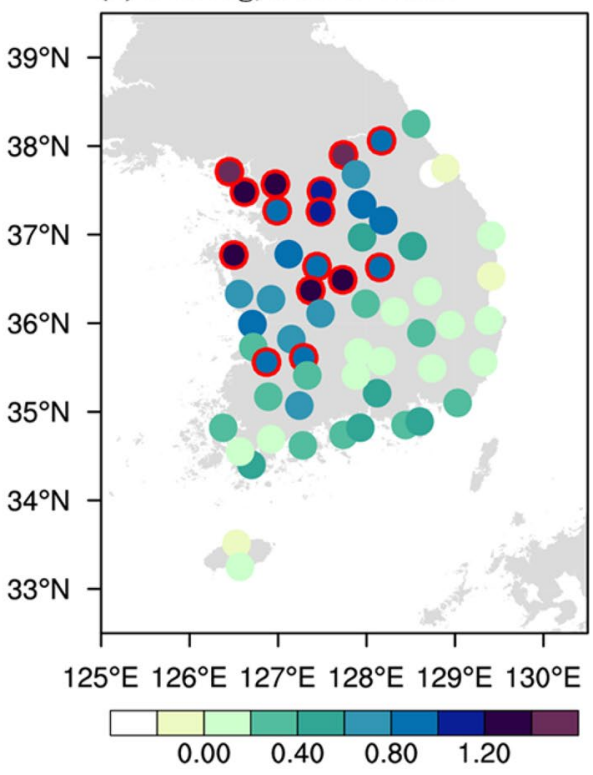


(a) Reg of JJA Z500 on EASMI

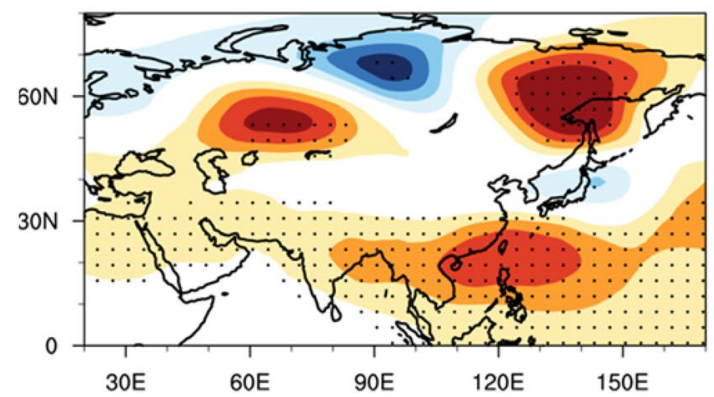

(c) Reg of JJA Z850 on EASMI

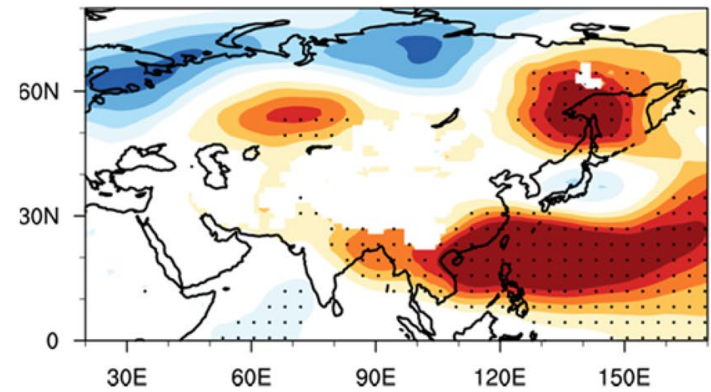

Fig. 4 Regression maps of the summer geopotential height anomalies (Unit: gpm) at a 500-hPa and c $850-\mathrm{hPa}$ on the EASMI. Partial regression maps of the summer geopotential height anomalies (Unit: gpm) at b 500-hPa and d $850-\mathrm{hPa}$ on May TASST after excluding

between SST EC1 and May TASST. Thus, the SVD results support our hypothesis that May TASST does significantly influence the EASM precipitation.

The quantitative assessments of the complex relationships are summarized in Table 2. Most of the correlation coefficients are significant at the $99 \%$ confidence level. The linkage between the EASMI and the preceding May TASST is evident with the correlation coefficient being 0.72 for the period 1979-2015. It is also apparent that the EASMI has a close relationship with SST EC1 (PR EC1) with the correlation coefficients reaching 0.65 (0.92), which is significant at the $99 \%$ confidence level. Although April-May (AM) NAO and DJF Nino3.4 are well known to affect the EASM through teleconnections (Ogi et al. 2003; Sung et al. 2006; Wu et al. 2009; Zuo et al. 2013), these two indices show relatively low correlations $(-0.43$ and 0.54) with the EASMI. Furthermore, the partial correlation coefficient between May TASST (preceding DJF Nino3.4) and the EASMI after excluding the effect of the preceding DJF Nino3.4 (May TASST) is $0.61(0.28)$, which is significant at the $99 \%(90 \%)$ confidence level. This indicates that TASST itself strongly affects the EASM variability, and that the connection between the EASM and the preceding DJF Nino3.4 is strongly determined by May TASST. (b) ParReg of JJA Z500 on May TASST

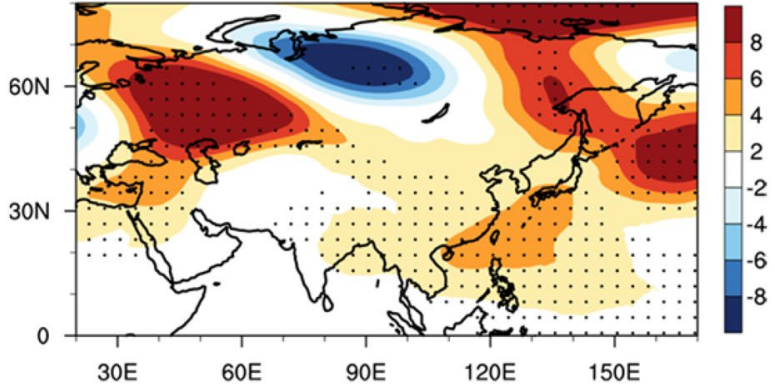

(d) ParReg of JJA Z850 on May TASST

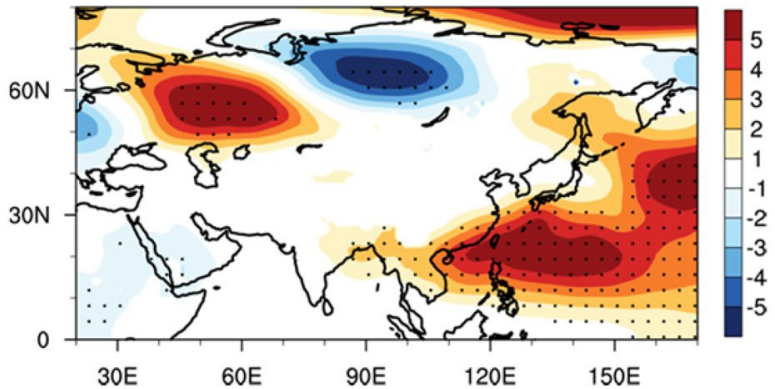

the effect of the preceding DJF Nino3.4. The dots indicate the areas where the correlation coefficients are significant at the $90 \%$ confidence level

\section{Possible mechanisms}

The analyses presented above revealed a strong coupling between May TASST and the EASM circulation system. Next, we applied partial regression analysis to investigate the mechanisms responsible for the connection between the EASM and the preceding May TASST. Figure $6 \mathrm{a}$ and b show the partial regression of May and JJA SST anomalies, respectively, on the preceding May TASST. Significant positive SST anomalies are clearly evident in the tropical Atlantic area. These SST signals appear to persist from spring through summer due to the oceanic thermal memory (Fig. 6b), which is quantified by the correlation coefficient of 0.83 between the May and JJA TASSTs (statistically significant at the $99 \%$ confidence level). These results agree well with previous studies (Wu et al. 2009; Zuo et al. 2013; Ham et al. 2013a).

The Pacific-Atlantic teleconnection induced by the persistence of the TASST anomalies is one of the possible mechanisms for this May TASST-EASM coupling, as has been introduced in simplified form by previous studies (McGregor et al. 2014; Li et al. 2016; Ham et al. 2017). Figure 7 shows the partial regression maps of the JJA precipitation, horizontal wind, velocity potential, and 
(a) JJA PR

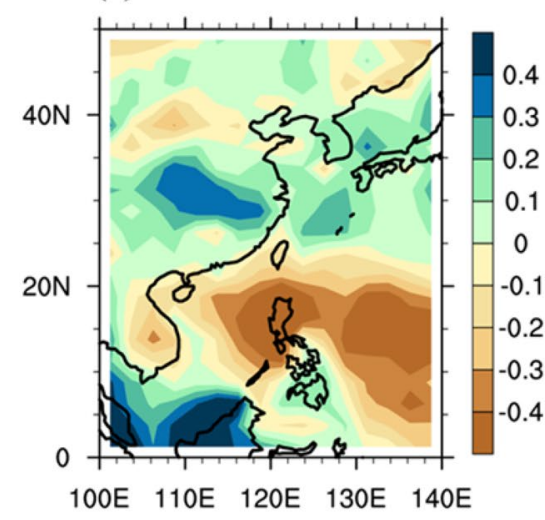

(b) May SST

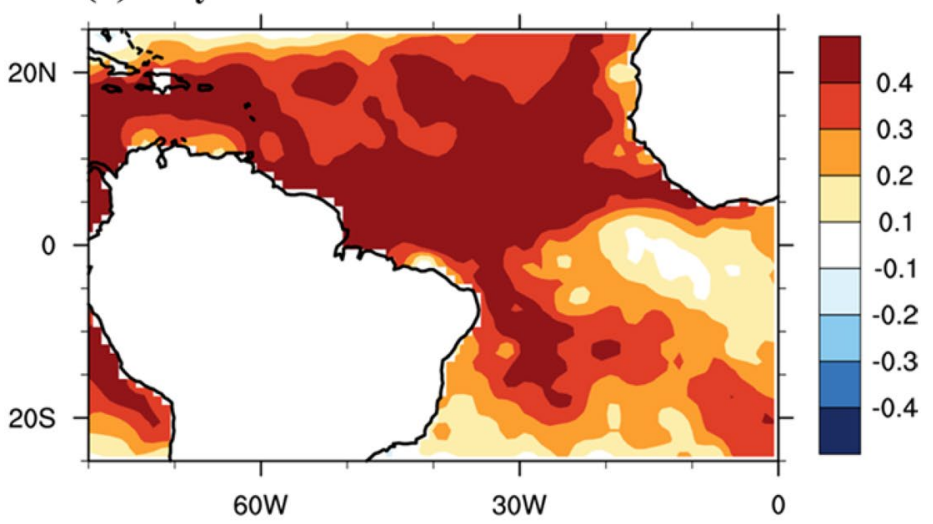

(c) Expansion coefficients

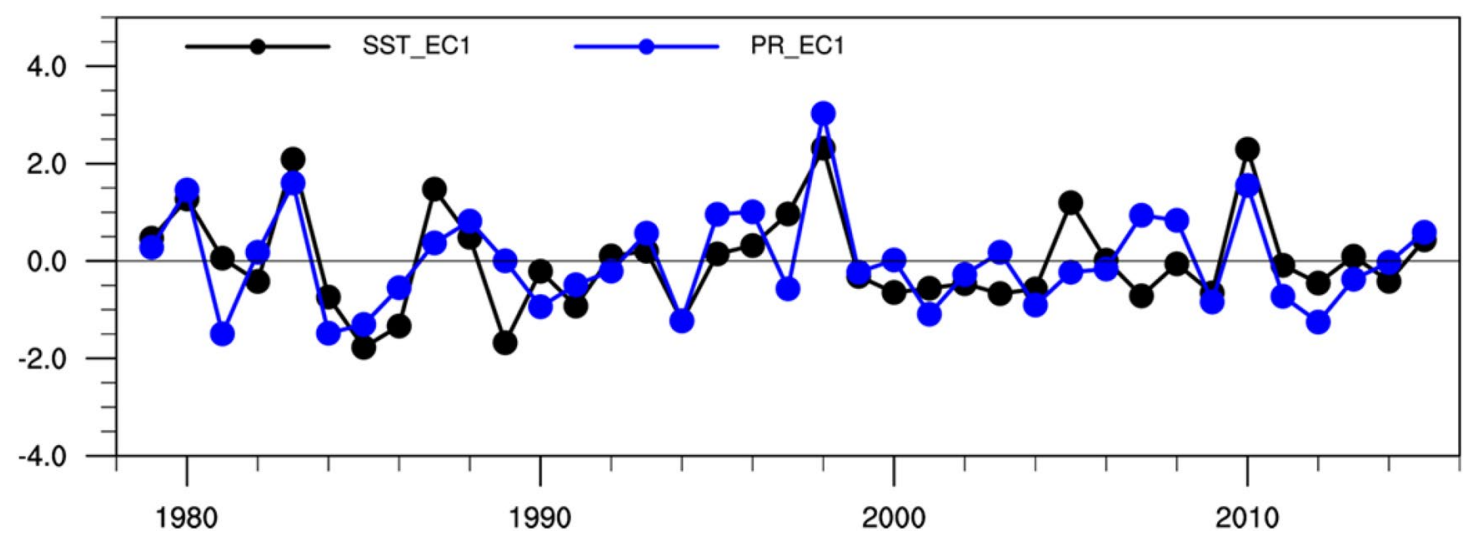

Fig. 5 Heterogeneous correlation patterns of the a JJA precipitation (Unit: mm/day) over East Asia and b May SST (Unit: ${ }^{\circ} \mathrm{C}$ ) in the tropical Atlantic for the first SVD mode. $\mathbf{c}$ Time series of the normalized expansion coefficients

Table 2 Correlation coefficients among the EASMI, May TASST, DJF Nino3.4, AM NAO, SST EC1, and PR EC1 for the period 19792015. The values in parentheses indicate the partial correlation coeffi- cient between May TASST (preceding DJF Nino3.4) and the EASMI after excluding the effect of the preceding DJF Nino3.4 (May TASST)

\begin{tabular}{lllrr}
\hline & May TASST & DJF Nino3.4 & AM NAO & SST EC1 \\
\hline EASMI & $0.72^{* *}$ & $0.54^{* *}$ & $-0.43^{* *}$ & $0.65^{* *}$ \\
May TASST & $\left(0.61^{* *}\right)$ & $\left(0.28^{*}\right)$ & & $0.92^{* *}$ \\
DJF Nino3.4 & & $0.52^{* *}$ & $-0.46^{* *}$ & $0.88^{* *}$ \\
AM NAO & & -0.01 & $0.64^{* *}$ & $0.70^{* *}$ \\
SST EC1 & & & & $0.55^{* *}$ \\
\end{tabular}

*Significant at the $95 \%$ confidence level

$* *$ Significant at the $99 \%$ confidence level

divergent wind anomalies on May TASST. The positive precipitation anomaly response to May TASST appears over the north tropical Atlantic where the ITCZ is located. This positive precipitation anomaly in the off-equatorial Atlantic (i.e., enhanced Atlantic ITCZ) can induce a Gilltype Rossby wave response (Gill 1980) over the subtropical eastern Pacific, with an anomalous low-level cyclonic circulation (Fig. 7b) and westward extension of the downward branch of the Pacific Walker circulation (Fig. 7c). At the same time, the descending branch of Pacific Walker circulation is simultaneously accompanied by anomalous upper-level convergence and low-level divergence in the $\mathrm{CP}$ region (Fig. $7 \mathrm{~b}$ and c). The associated anomalous low-level divergence causes an equatorial easterly wind 
Fig. 6 Partial regression maps of the $\mathbf{a}$ May and $\mathbf{b}$ summer SST anomalies (Unit: ${ }^{\circ} \mathrm{C}$ ) on May TASST after excluding the effect of the preceding DJF Nino3.4. The dots in (a) and (b) indicate the areas where the correlation coefficients are significant at the $90 \%$ confidence level (a) ParReg of May SST on May TASST without DJF NINO3.4

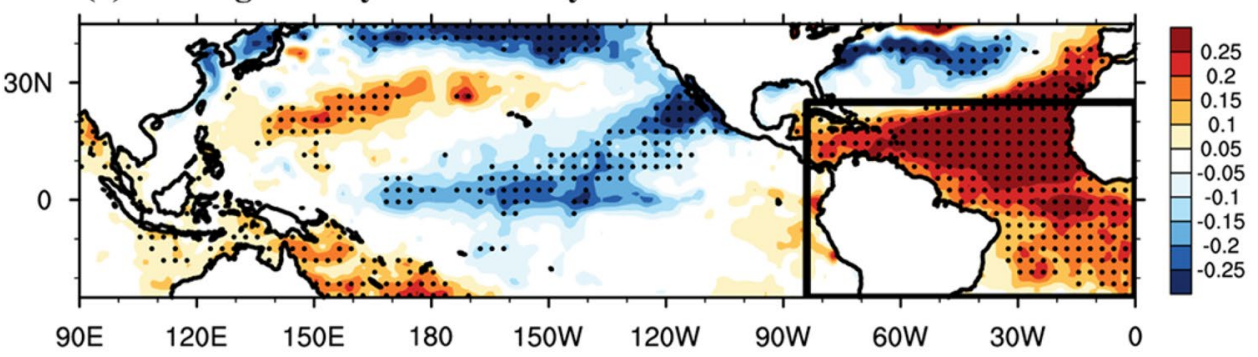

(b) ParReg of JJA SST on May TASST without DJF NINO3.4

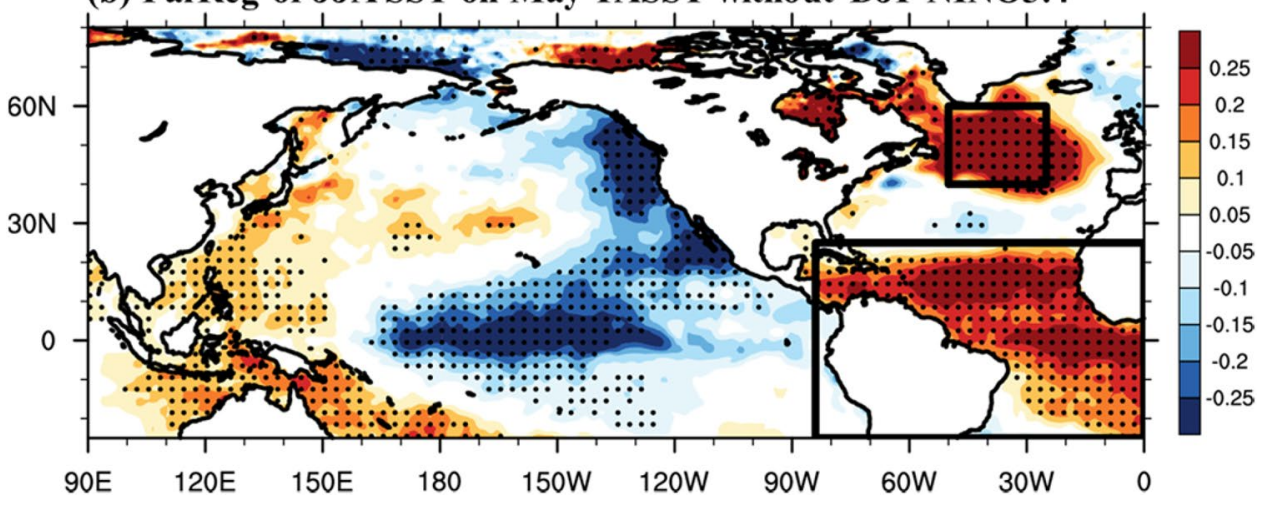

anomaly in the western $\mathrm{CP}$ region (Fig. 7b). The equatorial easterly wind anomaly enhances the equatorial upwelling, resulting in a negative SST anomaly (Fig. 6b), which not only decreases the precipitation (Fig. 7a; weakened Pacific ITCZ) but also produces anomalous low-level anticyclonic circulation over the western North Pacific as a Gill-type atmospheric response. This anticyclonic circulation over the western North Pacific can bring warm and humid air to higher latitudes, resulting in the enhanced rainfall over the $\mathrm{BCM}$ region.

In addition to the westward relay of the Atlantic signal, further evidence for the May TASST-EASM connection is evident in the partial regression maps of $300-\mathrm{hPa}$ geopotential height and the associated WAF anomalies upon May TASST (Fig. 8). The May TASST can induce an upper-level anticyclonic circulation anomaly over the far eastern Pacific and the Atlantic $\left(110^{\circ} \mathrm{W}-65^{\circ} \mathrm{W}\right)$ as a Gilltype response. The associated baroclinic wave response (low-level cyclonic circulation and upper-level anticyclonic circulation anomalies in Figs. $7 \mathrm{~b}$ and 8a, respectively) increases the precipitation over the eastern Pacific ITCZ region $\left(110^{\circ} \mathrm{W}-80^{\circ} \mathrm{W}\right.$; Fig. $\left.7 \mathrm{a}\right)$, which in turn produces another Gill-type Rossby wave response over the eastern North Pacific $\left(145^{\circ} \mathrm{W}-105^{\circ} \mathrm{W}\right.$; Fig. 8a; Wang et al. 2007 and 2008b; Barimalala et al. 2012). These wave responses near the subtropical westerly jet region (Fig. 8a) produce RWS associated with advection of absolute vorticity and vorticity stretching by the divergent flow. That is, the positive RWS anomaly prevails over the eastern North Pacific and the western North Atlantic (Fig. 8b). The perturbed Rossby wave in turn propagates eastward from the eastern Pacific to the Okhotsk Sea along the jet stream waveguide, which features remarkably positive geopotential anomalies in the Ural Mountains and the Okhotsk Sea, but negative anomalies in central Europe and Siberia, particularly to the northwest of Lake Baikal (Fig. 8a). This pattern closely resembles the regression maps shown in Fig. 4, indicating the quasi-barotropic structure. In particular, the anticyclonic anomaly over the Okhotsk Sea is known to play an important role in the EASM variability (Wu et al. 2009; Zuo et al. 2013; Park and Ahn 2014; Yim et al. 2014; Oh et al. 2018). The anomalous anticyclonic circulation with barotropic structure over the Okhotsk Sea can transport cold air to lower latitudes. This cold air mass can be combined with the warm and humid air mass induced by the anomalous Philippine high, causing the enhanced subtropical frontal rainfall over the BCM region (Yim et al. 2014; Oh et al. 2018). In line with the zonal wave-train pattern, the associated WAF propagates eastward from the eastern Pacific to the Okhotsk Sea along the jet stream waveguide (Fig. 8c). Hence, the zonal wavetrain pattern is another possible mechanism for the linkage between May TASST and the EASM.

According to the previous studies, several factors are known to force the Rossby wave train prevailing over the northern Eurasia, such as tripolar SST in the North Atlantic (Wu et al. 2009, 2012; Zuo et al. 2013; Zheng et al. 2016), and tropical Atlantic SST (Watanabe and Kimoto 2000; $\mathrm{Li}$ et al. 2007). However, the relative roles of tropical and 
Fig. 7 Partial regression maps of a summer precipitation (Unit: $\mathrm{mm} /$ day, shading), b horizontal wind anomalies at $850-\mathrm{hPa}$ (Unit: $\mathrm{m} / \mathrm{s}$, vector), and $\mathbf{c}$ divergent winds (Unit: $\mathrm{m} / \mathrm{s}$, vector), and $300-\mathrm{hPa}$ velocity potential (Unit: $10^{6} \mathrm{~m}^{2} / \mathrm{s}$, shading) on May TASST after excluding the effect of the preceding DJF Nino3.4. The dots in (a) and (c) indicate the areas where the correlation coefficients are significant at the $90 \%$ confidence level. Only vectors statistically significant at the $90 \%$ confidence level are shown in (b) (a) ParReg of JJA PR on May TASST without DJF NINO3.4

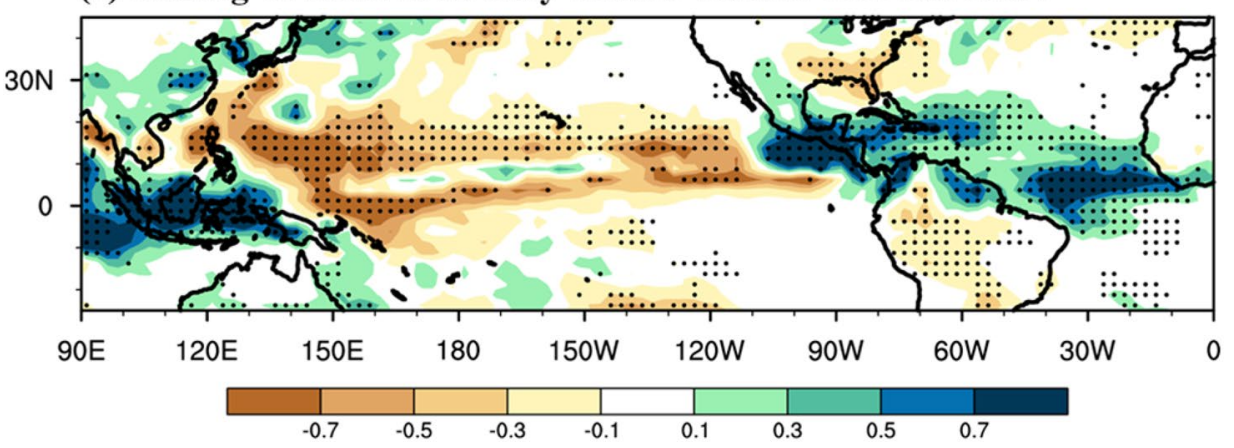

(b) ParReg of JJA UV850 on May TASST without DJF NINO3.4

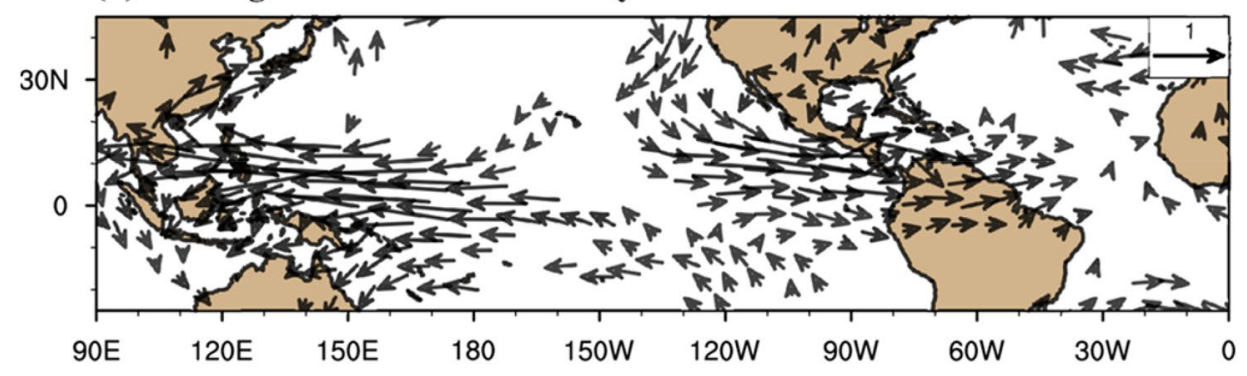

(c) ParReg of JJA DIV wind \& VP on May TASST without DJF NINO3.4

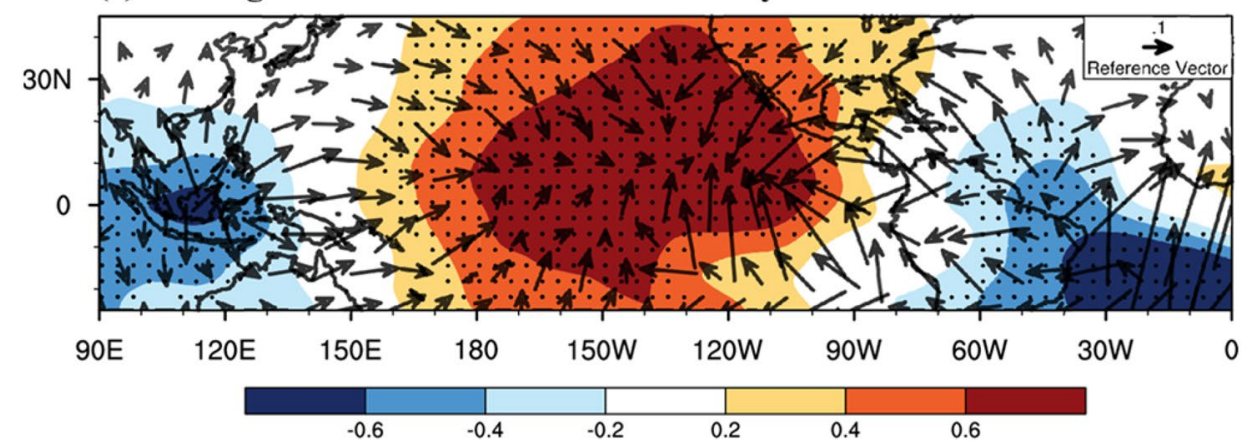

extratropical Atlantic SST anomalies in affecting Rossby wave propagation remain unclear. To quantitatively clarify this issue, we performed correlation, scatter diagram and composite analyses. For this, the subpolar SST index was defined as the area-averaged JJA SST anomalies over $40^{\circ} \mathrm{N}-60^{\circ} \mathrm{N}, 50 \mathrm{~W}^{\circ}-20^{\circ} \mathrm{W}$ where the correlation coefficients between May TASST and north Atlantic SST anomalies during JJA exceed the $90 \%$ confidence level (upper black rectangle in Fig. $6 \mathrm{~b}$ ). In addition, on the basis of the Rossby wave train response to the May TASST, Gill-type response and Okhotsk indices were defined by area averaging the $300-\mathrm{hPa}$ geopotential height anomalies over $15^{\circ} \mathrm{N}-45^{\circ} \mathrm{N}, 145 \mathrm{~W}^{\circ}-65^{\circ} \mathrm{W}$ (left black rectangle in Fig. 8a) and $50^{\circ} \mathrm{N}-70^{\circ} \mathrm{N}, 120 \mathrm{E}^{\circ}-152^{\circ} \mathrm{E}$ (right black rectangle in Fig. 8a), respectively.

Table 3 shows the correlation coefficients among TASST, subpolar SST, Gill-type response and Okhotsk indices. The results reveal a strong co-variability between May TASST and subpolar SST, which are associated with the North Atlantic SST tripole pattern. The tripolar SST in the North Atlantic is well known to excite the Rossby wave train prevailing over the northern Eurasia (Wu et al. 2009, 2012; Zuo et al. 2013). However, the tropical and extratropical Atlantic SST anomalies play different roles in affecting Rossby wave propagation. It is apparent that the May TASST index has a close relationship with both the JJA Gill-type response and the Okhotsk indices, with correlation coefficients reaching 0.75 and 0.34 , which are significant at the $99 \%$ and $95 \%$ confidence levels, respectively. Meanwhile, subpolar SST has an insignificant relationship with the Okhotsk high during JJA with a correlation coefficient of 0.28 . Thus it seems probable that the Gill-type response in the eastern Pacific can link the May TASST and JJA Okhotsk high. These relationships are further supported by the partial correlation analysis, which produced a partial correlation coefficient of 0.34 between the JJA Gill-type response and the Okhotsk indices after excluding the effect of subpolar Atlantic SST. 
Fig. 8 Partial regression maps of a $300 \mathrm{hPa}$ geopotential height anomaly (Unit: gpm), b Rossby wave source (RWS; Unit: $\left.1 \times 10^{-11} \mathrm{~s}^{-2}\right)$, and $\mathbf{c}$ associated wave activity flux (WAF; Unit: $\mathrm{m}^{2} / \mathrm{s}^{2}$ ) on May TASST after excluding the effect of the preceding DJF Nino3.4. The dots in (a) indicate the areas where the correlation coefficients are significant at the $90 \%$ confidence level. The black rectangles in (a) and (b) represent the region where the Gill-type response index is defined. Shading in (c) denotes the climatological $300 \mathrm{hPa}$ zonal wind (Unit: $\mathrm{m} / \mathrm{s}$ ) during boreal summer (a) ParReg of JJA Z300 on May TASST without DJF NINO3.4

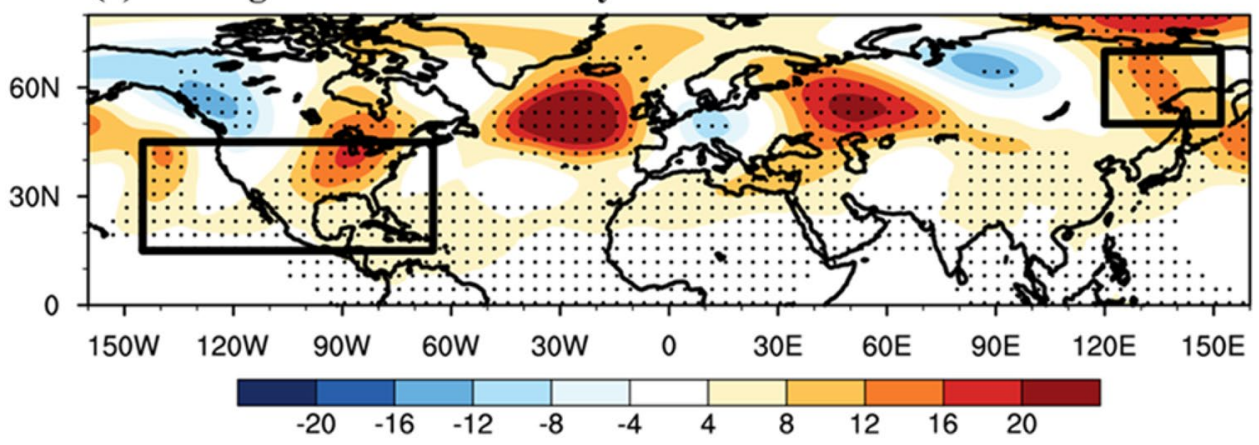

(b) ParReg of JJA RWS on May TASST without DJF NINO3.4

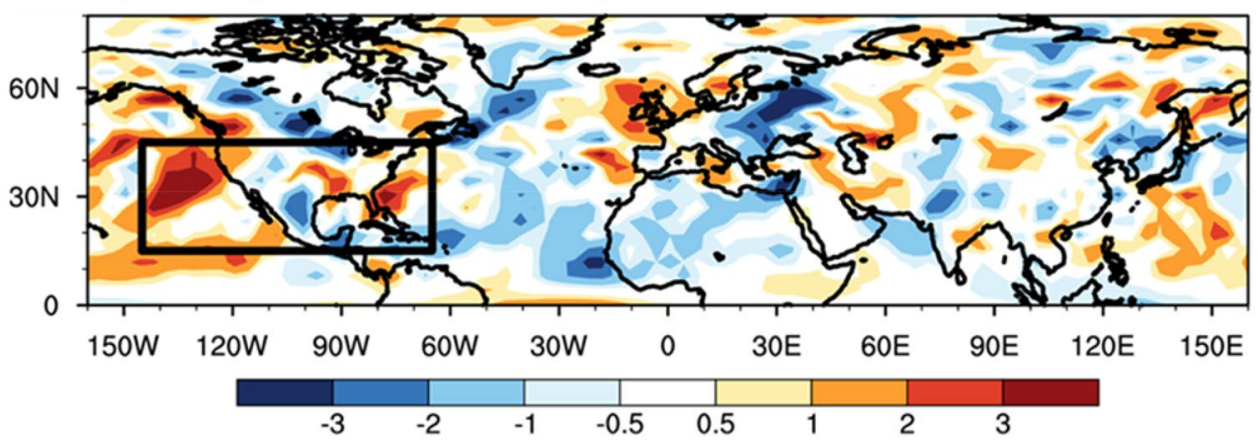

(c) ParReg of JJA WAF on May TASST without DJF NINO3.4

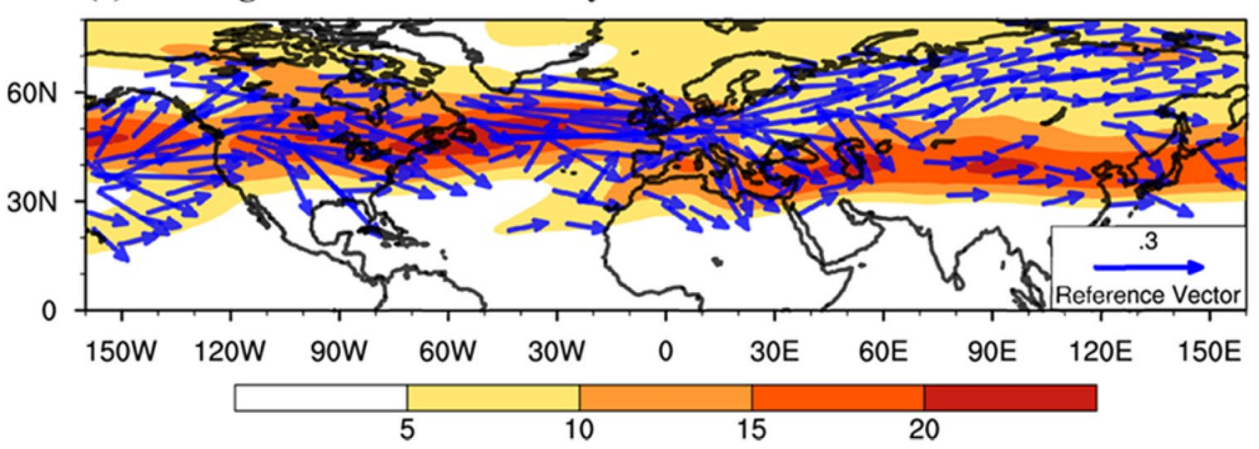

Figure 9 shows the scatter diagram of the Okhotsk index associated with the normalized JJA subpolar SST and Gilltype response indices. It is likely that the sign of the JJA Okhotsk index is mainly impacted by the Gill-type Rossby

Table 3 Correlation coefficients among subpolar SST, Gill-type response and Okhotsk indices for 1979-2015

\begin{tabular}{llll}
\hline & JJA subpolar SST & $\begin{array}{l}\text { JJA } \\
\text { Gill-type } \\
\text { response }\end{array}$ & JJA Okhotsk \\
& & $0.75^{* *}$ & $0.34^{*}$ \\
MAY TASST & $0.51^{* *}$ & $0.38^{*}$ & 0.28 \\
JJA subpolar SST & & & $0.40^{* *}$ \\
JJA Gill-type response & &
\end{tabular}

*Significant at the $95 \%$ confidence level

**Significant at the $99 \%$ confidence level wave response, rather than by subpolar Atlantic SST. That is, the value of the Okhotsk index tends to be positive (negative) when the value of the Gill-type response index is positive (negative). This further supports the relative role of the May TASST variability on the eastward propagation of the Rossby wave train along the westerly jet stream over the northern Eurasia.

In order to separate the relative roles of the JJA subpolar SST and Gill-type response, composite analysis was conducted. All years were categorized into two groups based on the JJA subpolar SST and Gill-type response indices. One group is for the subpolar Atlantic SST warming accompanied by a strong anticyclonic anomaly in the eastern Pacific (hereafter, the strong Gill-type response case; i.e., both subpolar SST and Gill-type response indices are greater than their 0.5 standard deviation), and the other is for the subpolar 


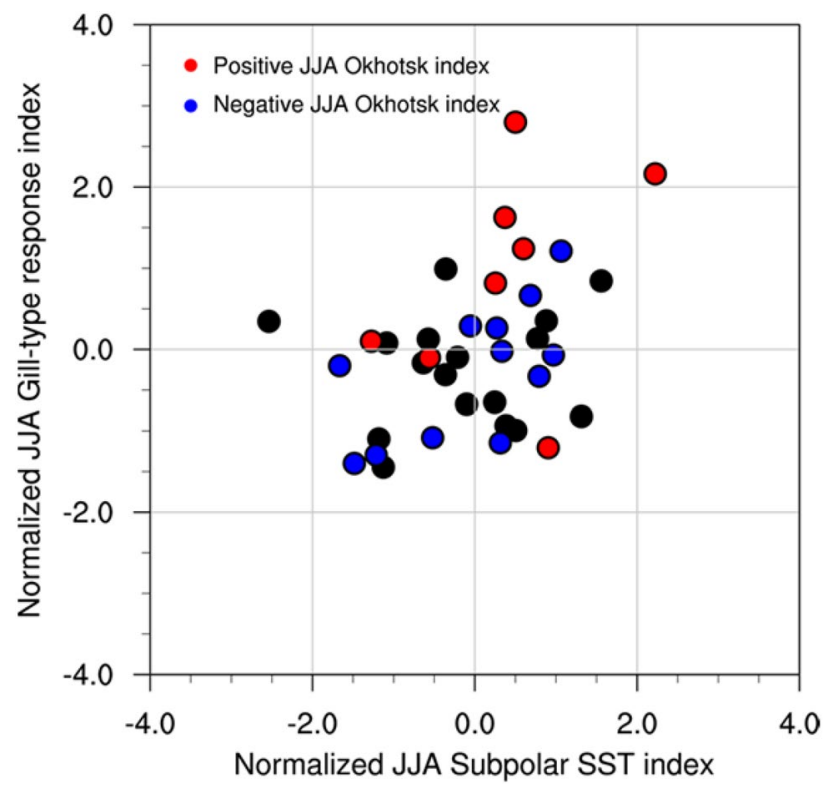

Fig. 9 Scatter diagram between the normalized JJA subpolar SST and Gill-type response indices. The red (blue) dots denote events when the JJA Okhotsk index is above (below) $0.5(-0.5)$ standard deviation

Atlantic SST warming only (hereafter, the weak Gill-type response case; i.e., the subpolar SST index is above 0.5 standard deviation and the Gill-type response index is less than or equal to 0.5 standard deviation).

Figure 10a shows composites of JJA 300-hPa geopotential height for strong and weak Gill-type response cases. In the former strong case, the Rossby wave train with the strong Okhotsk high develops during JJA, which is similar to the result shown in Fig. 8a. In contrast, when the Gill-type response is weak, the Rossby waves may not propagate far from their source. This suggests that the Gill-type response derived from May TASST plays some role in modulating both Rossby wave propagation and the Okhotsk high. Composites of JJA SST for both cases can further confirm the relative role of TASST on the Okhotsk high (Fig. 10b). TASST (subpolar SST) warming only appears in the case of the strong Gill-type response (both cases) during the boreal summer season, while there is no significant signal over the tropical Atlantic in the weak Gill-type response case. Furthermore, we analyzed composites of JJA 300-hPa geopotential height for tropical Atlantic SST warming-only case (i.e., the subpolar SST index is less than or equal to 0.5 standard deviation and the Gill-type response index is above 0.5 standard deviation; data not shown). In this case, there is no significant Rossby wave signal over the northern Eurasia. This implies that the strong coupling among TASST, subpolar SST, and Gill type response may excite the Rossby wave train which tends to travel farther into the Sea of Okhotsk.

To support the observational findings, the 31 CMIP5 historical simulations were utilized for the period 19612005. Figure 11 shows the partial correlation coefficients derived from 31 individual CMIP5 models after removing the effects of the preceding wintertime Nino3.4. Most GCMs, except three (HadCM3, IPSL-CM5ALR, and MPI-ESM-LR), can simulate the positive May TASST-EASM relationship. In particular, thirteen models (CNRM-CM5-2, GFDL-ESM2 M, IPSL-CM5B-LR, MIROC5; NorESM1-ME, CMCC-CMS, MRI_CGCM3, GFDL-CM2.1, IPSL-CM5A-MR, MIROC-ESM, (a) JJA Z300 (strong Gill-type response case)

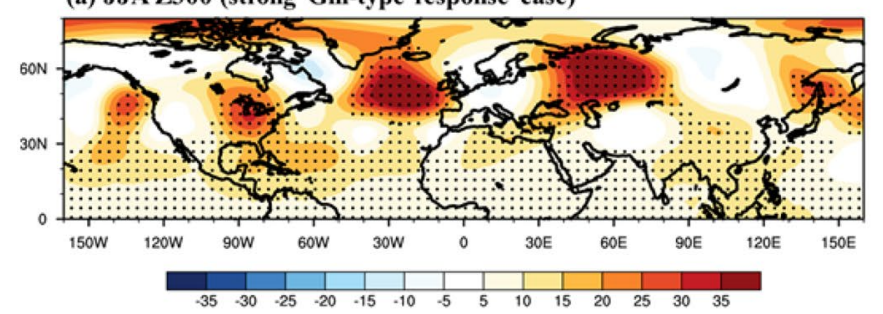

(c) JJA SST (strong Gill-type response case)

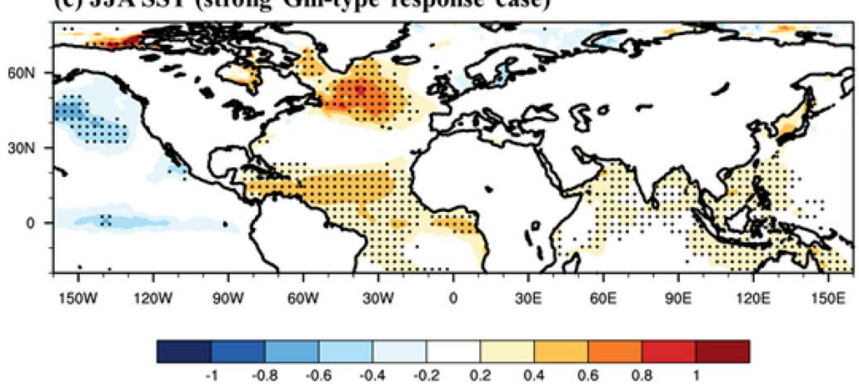

(b) JJA Z300 (weak Gill-type response case)

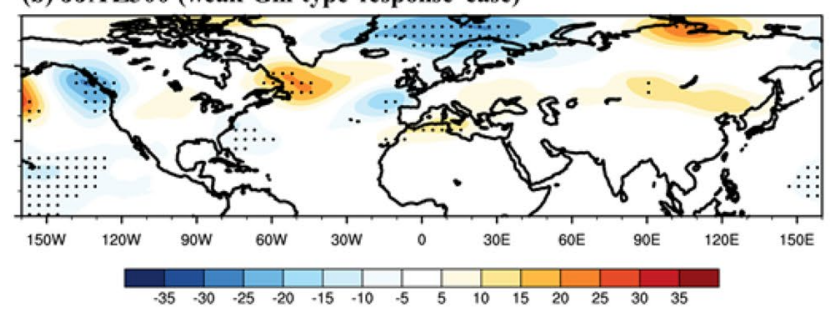

(d) JJA SST (weak Gill-type response case)

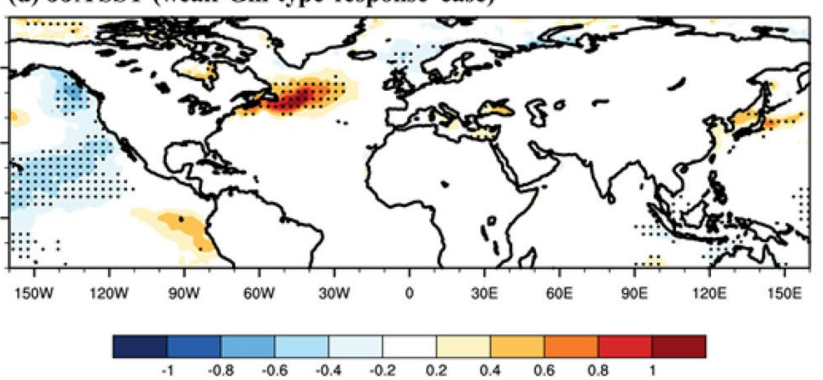

Fig. 10 Composites of JJA 300-hPa geopotential height (a, b) and SST (c, d) anomalies for strong and weak Gill-type response cases. The dots indicate the areas where the correlation coefficients are significant at the $90 \%$ confidence level based on the two-tailed student's $t$ test 
Fig. 11 Partial correlation coefficients between May TASST and the EASMI after excluding the effect of the preceding DJF Nino3.4 using the 31 Coupled Model Intercomparison Project Phase 5 (CMIP5) historical simulations. The red (blue) bars indicate the areas where the correlation coefficients are significant at the $99 \%(95 \%)$ confidence level
ParCorr btw May TASST and EASMI without DJF NINO3.4

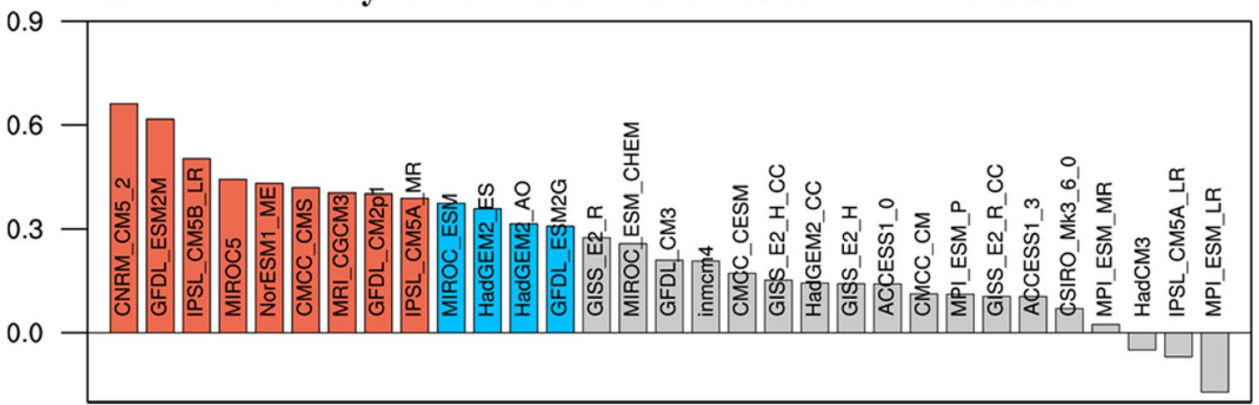

HadGEM2-ES, HadGEM2-AO, and GFDL-ESM2G) show better performance in simulating the remote impact of the tropical Atlantic on the EASM variability with correlation coefficients ranging from 0.31 to 0.66 , which are significant at the $95 \%$ confidence level, although the CMIP5 models appear to predominantly underestimate the observed relationship.
Using the thirteen models, we performed multi-model ensemble analysis in order to confirm the proposed mechanisms. The multi-model ensemble mean is calculated based on the equally weighted average of the thirteen models that can capture the significant relationship between the tropical Atlantic Ocean and the EASM variability. Figure 12 shows the partial regression maps of summer precipitation,
Fig. 12 Partial regression maps of summer a precipitation (Unit: $\mathrm{mm} /$ day, shading), b horizontal wind anomalies at 850-hPa (Unit: $\mathrm{m} / \mathrm{s}$, vector), and c geopotential height anomaly (Unit: gpm) at 300-hPa on May TASST after excluding the effect of the preceding DJF Nino3.4. The dots in (a) and (c) indicate the areas where the correlation coefficients are significant at the $90 \%$ confidence level. Only vectors statistically significant at the $90 \%$ confidence level are shown in (b) (a) CMIP5; ParReg of JJA PR on May TASST without DJF NINO3.4

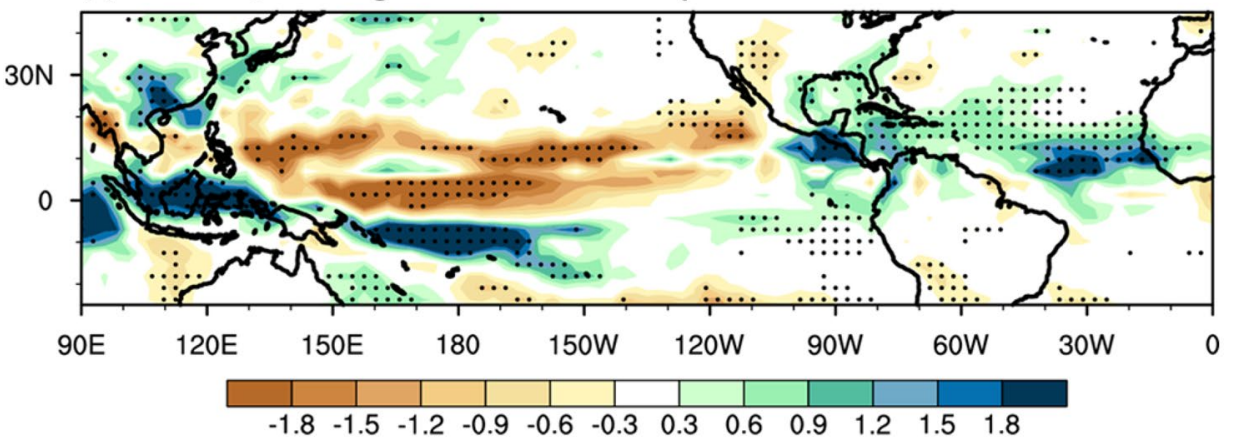

(b) CMIP5; ParReg of JJA UV850 on May TASST without DJF NINO3.4

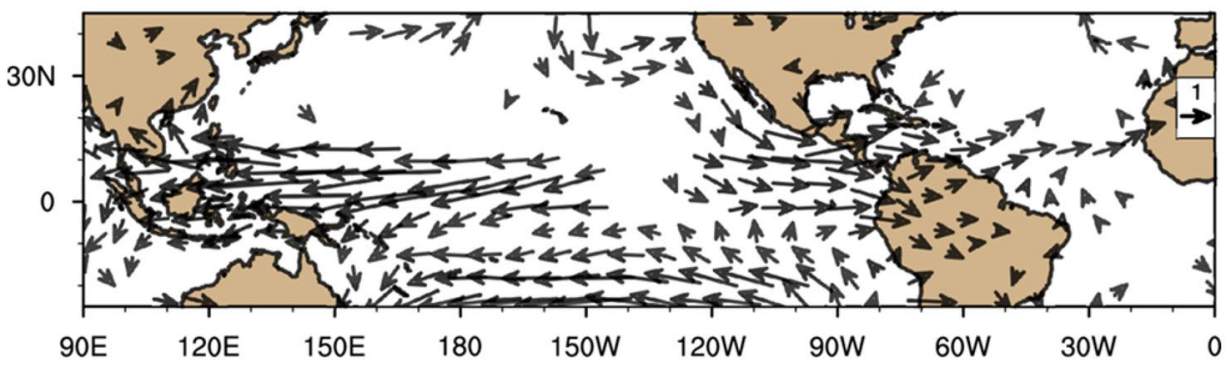

(c) CMIP5; ParReg of JJA Z300 on May TASST without DJF NINO3.4

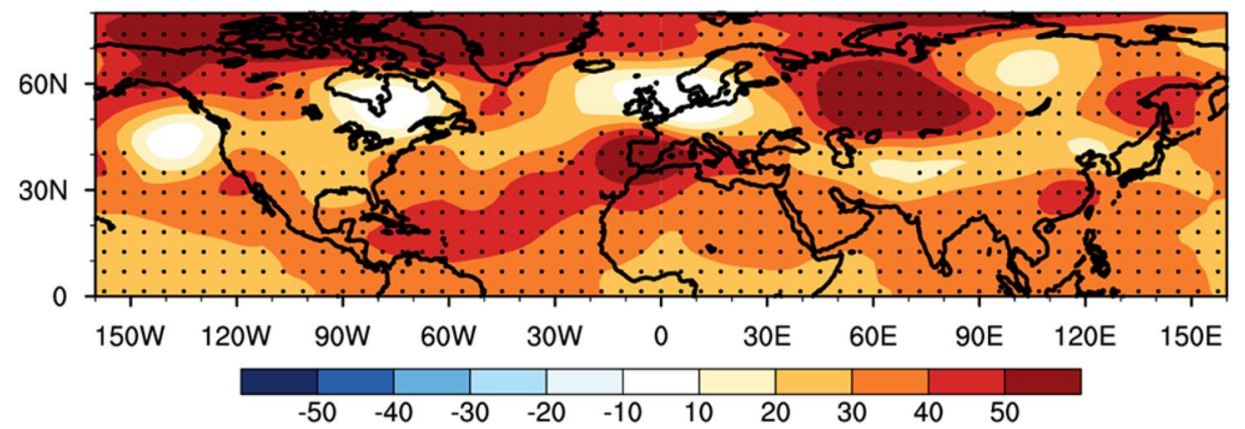


Fig. 13 Schematic diagram of the proposed mechanisms responsible for the May TASSTEASM connection between the EASM and preceding May TASST

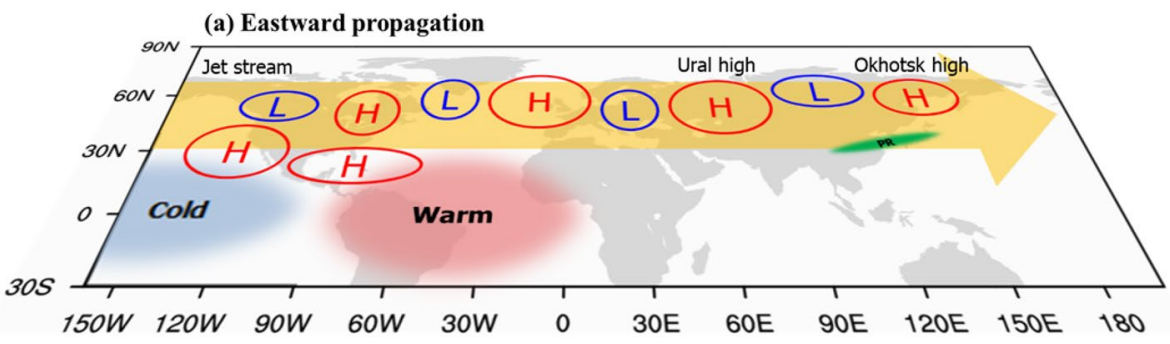

(b) Westward propagation

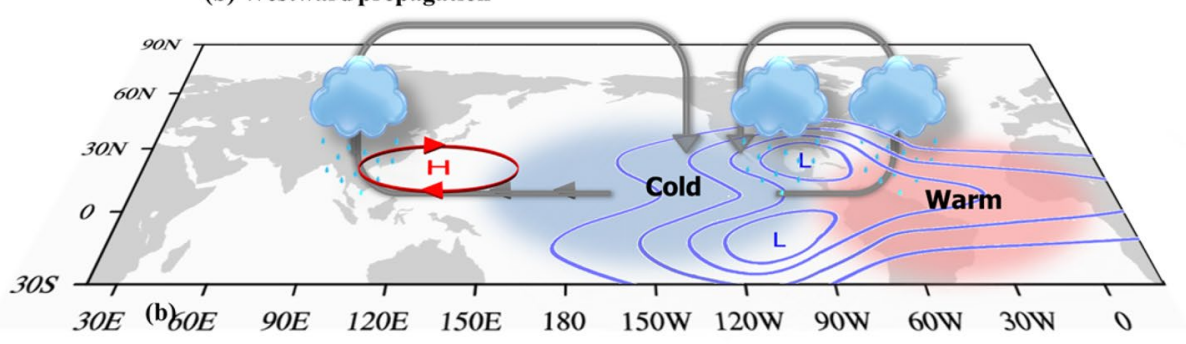

850-hPa horizontal wind, and 300-hPa geopotential height anomalies on May TASST. According to the ensemble results, the westward relay of the Atlantic signal can be seen to some extent from the Pacific through the Atlantic region, with the cyclonic flow over the eastern Pacific, low-level divergence in the CP region, and the intensified Walker circulation over the tropical Pacific Ocean. This Pacific-Atlantic teleconnection pattern well corresponds to the observational result shown in Fig. 7. Also, the significant positive geopotential height anomalies in the upper troposphere, especially over the Ural Mountains and the Okhotsk Sea, bear some resemblance with those shown in Fig. 8a. The two teleconnection patterns appearing in the lower (Fig. 12b) and upper (Fig. 12c) atmosphere can affect the EASM according to the observational evidence. These results support our hypothesis that the preceding May SST anomalies over the tropical Atlantic can potentially affect the EASM.

\section{Summary and conclusions}

This study has demonstrated the influence of May TASST on the following EASM variability and we propose two possible mechanisms for this coupling. Our findings confirm the May TASST-EASM coupling with a correlation coefficient of 0.72 for the period 1979-2015. That is, the response of JJA precipitation to May TASST yields the meridional tripole pattern. In particular, the positive (negative) precipitation anomalies are clearly evident in the subtropical frontal area and Maritime Continent (western North Pacific). This tripole pattern closely resembles the EASM. In addition, the SVD results further support our hypothesis that May TASST does significantly influence the EASM precipitation.
We also found evidence that two atmospheric teleconnections propagating in both east and west directions are the key physical mechanisms responsible for the May TASSTEASM connection. That is, the positive TASST during late spring can persist through the subsequent summer, which in turn strengthens the off-equatorial Atlantic ITCZ. The intensified ITCZ induces the Gill-type atmospheric response, with the westward extension of the downward branch of the Pacific Walker circulation. The anomalous low-level divergence associated with the westward extension of the Walker circulation can cause an equatorial easterly wind anomaly in the western $\mathrm{CP}$ region, which enhances the equatorial upwelling, leading to a negative SST anomaly. That in turn induces anomalous anticyclones in the lower troposphere over the Philippine Sea as a Gill-type atmospheric response. On the other hand, the Gill-type atmospheric response derived from May TASST produces an RWS near the subtropical westerly jet region. The perturbed Rossby wave then propagates eastward from the eastern Pacific to the Okhotsk Sea along the jet stream waveguide, which causes the anomalous tropospheric anticyclone with barotropic structure over the Okhotsk Sea. In relationship to this, we further demonstrated that the sign of the JJA Okhotsk high is mainly impacted by the tropical SST rather than by the subpolar SST over the Atlantic. Consequently, the anomalous anticyclonic circulation over the Philippine Sea (Okhotsk Sea) brings warm and humid (cold) air to higher latitudes (lower latitudes). These two different types of air mass merge over the Baiu-Meiyu-Changma region, causing the enhanced subtropical frontal rainfall. The mechanisms discussed above are shown schematically in Fig. 13.

Our findings suggest that the May TASST index can to some extent be used to predict the EASM variability. To assess its predictive capability, leave-one-out 
Fig. 14 Time series of observed and cross-validated estimates of the EASMI

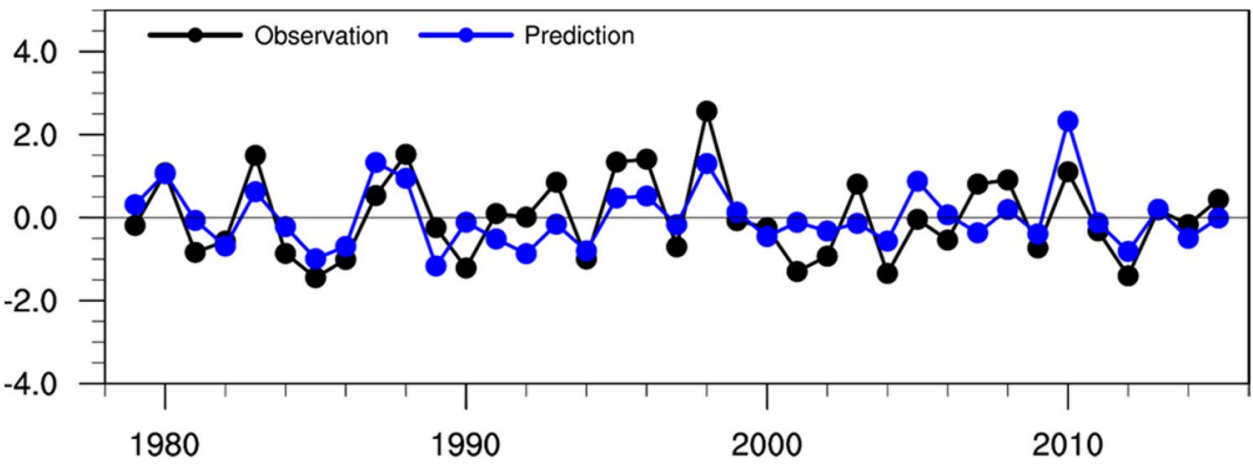

cross-validation method was applied (Wilks 1995). Figure 14 shows the time series of observed and cross-validated estimates of the EASMI. Although the variation amplitude of the predicted EASMI is smaller than that observed (standard deviation ratio between observed and predicted indices $=0.74$ ), these two time series significantly covariate over the entire period with a correlation coefficient of 0.67 , which is significant at the $99 \%$ confidence level. This implies that the May TASST could be a useful predictor for the EASM.

In conclusion, this study has newly revealed that the EASM system can be greatly affected by TASST during late spring. In particular, the inter-basin relationship between the tropical Atlantic Ocean and the EASM variability is clearly identified from the observational data and CMIP5 historical simulations, although the CMIP5 models appear to predominantly underestimate the observed relationship. However, the statistical approach used in this study still cannot completely explain the physical mechanisms responsible for the May TASST-EASM coupling. Explicitly clarifying the proposed mechanisms will require further model experiments.

Acknowledgement This study was financially supported by the $『 2019$ Post-Doc. Development Program』 of Pusan National University, and by the Korea Meteorological Administration Research and Development Program under Grant KMI2018-01213 and the Rural Development Administration Cooperative Research Program for Agriculture Science and Technology Development under Grant Project No. PJ01345205, Republic of Korea. We extend our thanks to Prof. Jong-Ghap Jhun, Dr. Vladimir N. Kryjov, and Prof. Kyong-Hwan Seo for valuable comments and suggestions which improve the quality of this paper.

Open Access This article is distributed under the terms of the Creative Commons Attribution 4.0 International License (http://creativeco mmons.org/licenses/by/4.0/), which permits unrestricted use, distribution, and reproduction in any medium, provided you give appropriate credit to the original author(s) and the source, provide a link to the Creative Commons license, and indicate if changes were made.

\section{References}

Adler RF et al (2003) The version-2 global precipitation climatology project (GPCP) monthly precipitation analysis (1979-Present). J Hydrometeorol 4:1147-1167
Alexander MA, Scott JD (2002) The influence of ENSO on air-sea interaction in the Atlantic. Geophys Res Lett 29:1701. https://doi. org/10.1029/2001GL014347

Ashok K, Behera SK, Rao SA, Weng H, Yamagata T (2007) El Niño Modoki and its possible teleconnection. J Geophys Res 112:C11007. https://doi.org/10.1029/2006JC003798

Barimalala R, Bracco A, Kucharski F (2012) The representation of the south tropical Atlantic teleconnection to the Indian Ocean in the AR4 coupled models. Clim Dyn 38:1147-1166

Bretherton CS, Smith C, Wallace JM (1992) An intercomparison of methods for finding coupled patterns in climate data. J Clim 5:541-560.

Chang C-P, Zhang Y, Li T (2000) Interannual and interdecadal variations of the East Asian summer monsoon and tropical Pacific SSTs. Part I: roles of the subtropical ridge. J Climate 13:4310 4325. https://doi.org/10.1175/1520-0442(2000)013\%3c431 0:IAIVOT\%3e2.0.CO;2

Choi Y-W, Ahn J-B, Kryjov VN (2016) November seesaw in northern extratropical sea level pressure and its linkage to the preceding wintertime Arctic Oscillation. Int J Climatol 36:1375-1386

Gill A (1980) Some simple solutions for heat-induced tropical circulation. Q J R Meteorol Soc 106:447-462

Gong DY, Ho C-H (2003) Arctic Oscillation signals in East Asian summer monsoon. J Geophys Res Atmos 108:4066. https://doi. org/10.1029/2002JD002193

Gong DY, Yang J, Kim S-J, Gao Y, Guo D, Zhou T, Hu M (2011) Spring Arctic Oscillation-East Asian summer monsoon connection through circulation changes over the western North Pacific. Clim Dyn 37:2199-2216

Ham Y-G, Kug J-S, Park J-Y, Jin FF (2013a) Sea surface temperature in the north tropical Atlantic as a trigger for El Niño/Southern Oscillation events. Nat Geosci 6:112

Ham Y-G, Kug J-S, Park J-Y (2013b) Two distinct roles of Atlantic SSTs in ENSO variability: North tropical Atlantic SST and Atlantic Niño. Geophys Res Lett 40:4012-4017

Ham Y-G, Kug J-S (2015) Role of north tropical Atlantic SST on the ENSO simulated using CMIP3 and CMIP5 models. Clim Dyn 45:3103-3117

Ham Y-G, Chikamoto Y, Kug J-S, Kimoto M, Mochizuki T (2017) Tropical Atlantic-Korea teleconnection pattern during boreal summer season. Clim Dyn 49:2649-2664

Hong J-Y, Ahn J-B (2015) Changes of early summer precipitation in the Korean Peninsula and nearby regions based on RCP Simulations. J Clim 28(9):3557-3578

Huang R, Wu Y (1989) The influence of ENSO on the summer climate change in China and its mechanism. Adv Atmos Sci 6:21-32

Huang R, Sun F (1992) Impacts of the tropical western Pacific on the East Asian summer monsoon. J Meteorol Soc Jpn 70:243-256

Jin F, Hoskins BJ (1995) The direct response to tropical heating in a baroclinc atmosphere. J Atmos Sci 52(3):307-319 
Kim S, Kug J-S (2018) What controls ENSO teleconnection to East Asia? Role of Western North Pacific precipitation in ENSO teleconnection to East Asia. J Geophys Res Atmos 123(18):10-406

Lee E-J, Yeh S-W, Jhun J-G, Moon B-K (2006) Seasonal change in anomalous WNPSH associated with the strong East Asian summer monsoon. Geophys Res Lett 33:L21702. https://doi. org/10.1029/2006GL027474

Li X, Xie SP, Gille ST, Yoo C (2016) Atlantic-induced pan-tropical climate change over the past three decades. Nat Clim Chang 6:275

Li S, Robinson WA, Hoerling MP, Weickmann KM (2007) Dynamics of the extratropical response to a tropical Atlantic SST anomaly. J Clim 20:560-574

Li S, Hou W, Feng G (2018) Atmospheric circulation patterns over East Asia and their connection with summer precipitation and surface air temperature in Eastern China during 1961-2013. J Meteor Res 32(2):203-218

Lim YK (2015) The East Atlantic/West Russia (EA/WR) teleconnection in the North Atlantic: climate impact and relation to Rossby wave propagation. Clim Dyn 44:3211-3222

McGregor S, Timmermann A, Stuecker MF, England MH, Merrifield M, Jin FF, Chikamoto Y (2014) Recent Walker circulation strengthening and Pacific cooling amplified by Atlantic warming. Nat Clim Chang 4:888

Nitta T (1987) Convective activities in the Tropical Western Pacific and their impact on the Norther Hemisphere summer circulation. J Meteor Soc Japan 64:373-390

Ogi M, Tachibana Y, Yamazaki K (2003) Impact of the wintertime North Atlantic Oscillation (NAO) on the summertime atmospheric circulation. Geophys Res Lett 30(13):1704

Oh H, Ha K-J, Timmermann A (2018) Disentangling impacts of dynamic and thermodynamic components on late summer rainfall anomalies in East Asia. J Geophys Res 123:8623-8633. https:// doi.org/10.1029/2018JD028652

Park Y-J, Ahn J-B (2014) Characteristics of atmospheric circulation over East Asia associated with summer blocking. J Geophys Res Atmos 119:726-738. https://doi.org/10.1002/2013JD020688

Park H-J, Kryjov VN, Ahn J-B (2018) One-month-lead predictability of asian summer monsoon indices based on the zonal winds by the APCC multimodel ensemble. J Clim 31(21):8945-8960

Rayner NA, Parker DE, Horton EB, Folland CK, Alexander LV, Rowell DP, Kent EC, Kaplan A (2003) Global analyses of sea surface temperature, sea ice, and night marine air temperature since the late nineteenth century. J Geophys Res 108:4407. https://doi. org/10.1029/2002JD002670

Rienecker MM et al (2011) MERRA-NASA's modern era retrospective analysis for research and applications. J Clim 24:3624-3648. https://doi.org/10.1175/JCLI-D-11-00015.1

Sardeshmukh PD, Hoskins BJ (1988) The generation of global rotational flow by steady idealized tropical divergence. J Atmos Sci 45:1228-1251

Seo K-H, Son J-H, Lee S-E, Tomita T, Park H-S (2012) Mechanisms of an extraordinary East Asian summer monsoon event in July 2011. Geophys Res Lett 39:L05704

Sun J, Wang H, Yuan W (2009) Role of the tropical Atlantic sea surface temperature in the decadal change of the summer North Atlantic Oscillation. J Geophys Res 114:D20110. https://doi. org/10.1029/2009JD012395

Sun J, Wang H (2012) Changes of the connection between the summer North Atlantic oscillation and the East Asian summer rainfall. J Geophys Res Atmos 117:D08110
Sung M-K, Kwon W-T, Baek H-J, Boo K-O, Lim G-H, Kug J-S (2006) A possible impact of the North Atlantic Oscillation on the east Asian summer monsoon precipitation. Geophys Res Lett 33:L21713

Takaya K, Nakamura H (2001) A formulation of a phase-independent wave-activity flux for stationary and migratory quasigeostrophic eddies on a zonally varying basic flow. J Atmos Sci 58:608-627

Wang B, Wu R, Fu X (2000) Pacific-East Asian teleconnection: How does ENSO affect East Asian Climate? J Clim 13:1517-1536

Wang B, Wu R, Lau KM (2001) Interannual variability of the Asian summer monsoon: Contrasts between the Indian and the western North Pacific-East Asian monsoons. J Clim 14(20):4073-4090

Wang C, Lee SK, Enfield DB (2007) Impact of the Atlantic warm pool on the summer climate of the Western Hemisphere. J Clim 20:5021-5040

Wang B, Wu Z, Li J, Liu J, Chang CP, Ding Y, Wu G (2008a) How to measure the strength of the East Asian Summer Monsoon. J Clim 21:4449-4463. https://doi.org/10.1175/2008jcli2183.1

Wang C, Lee SK, Enfield DB (2008b) Climate response to anomalously large and small Atlantic warm pools during the summer. J Clim 21:2437-2450

Watanabe M, Kimoto M (2000) Atmosphere-ocean thermal coupling in the North Atlantic: A positive feedback. Q J R Meteorol Soc 126:3343-3369

Wilks DS (1995) Statistical methods in the atmospheric sciences: an introduction. Academic Press, San Diego, p 467

Wu Z, Wang B, Li J, Jin FF (2009) An empirical seasonal prediction model of the east Asian summer monsoon using ENSO and NAO. J Geophys Res 114:D18120. https://doi.org/10.1029/2009j d011733

Wu Z, Li J, Jiang Z, He J, Zhu X (2012) Possible effects of the North Atlantic Oscillation on the strengthening relationship between the East Asian Summer monsoon and ENSO. Int J Climatol 32:794800. https://doi.org/10.1002/joc.2309

Xie SP, Hu K, Hafner J, Tokinaga H, Du Y, Huang G, Sampe T (2009) Indian Ocean capacitor effect on Indo- western Pacific climate during the summer following El Niñ. J Clim 22:730-747

Yang J, Liu Q, Xie SP, Liu Z, Wu L (2007) Impact of the Indian Ocean SST basin mode on the Asian summer monsoon. Geophys Res Lett 34:L02708. https://doi.org/10.1029/2006GL028571

Yim S-Y, Wand B, Xing W (2014) Prediction of early summer rainfall over South China by a physical-empirical model. Clim Dyn 43:1883-1891. https://doi.org/10.1007/s00382-013-2014-3

Yun K-S, Ha K-J, Wang B (2010) Impacts of tropical ocean warming on East Asian summer climate. Geophys Res Lett 37:L20809

Zheng F, Li J, Li Y, Zhao S, Deng D (2016) Influence of the summer NAO on the spring-NAO-based predictability of the East Asian summer monsoon. J Appl Meteorol Climatol 55:1459-1476

Zhou T, Gong D, Li J, Li B (2009) Detecting and understanding the multi-decadal variability of the East Asian summer monsoonrecent progress and state of affairs. Meteorol Z 18:455-467

Zuo J, Li W, Sun C, Xu L, Ren HL (2013) Impact of the North Atlantic sea surface temperature tripole on the East Asian summer monsoon. Adv Atmos Sci 30:1173-1186

Publisher's Note Springer Nature remains neutral with regard to jurisdictional claims in published maps and institutional affiliations. 